\title{
Research and Analysis of the Sino-US Agricultural Trade in Current Decade
}

\author{
Xiujuan Wang1,2, Jie Pan', Jilian $\mathrm{Hu}^{2 *}$ \\ ${ }^{1}$ College of Foreign Languages, Shandong Agricultural University, Taian, China \\ ${ }^{2}$ School of Economics and Management, Shandong Agricultural University, Taian, China \\ Email: xjw9007@126.com, *jlhu@sdau.edu.cn
}

How to cite this paper: Wang, X.J., Pan, J. and Hu, J.L. (2018) Research and Analysis of the Sino-US Agricultural Trade in Current Decade. Agricultural Sciences, 9, 14191431.

https://doi.org/10.4236/as.2018.911098

Received: August 15, 2017

Accepted: November 18, 2018

Published: November 21, 2018

Copyright () 2018 by authors and Scientific Research Publishing Inc. This work is licensed under the Creative Commons Attribution International License (CC BY 4.0).

http://creativecommons.org/licenses/by/4.0/

\begin{abstract}
China has a large population, so the supply of agricultural products is very essential, and agricultural trade plays an important role. According to the data from the United Nations' commodity trade, the rate of agricultural products trade development between China and the United States is declining since 2012, and China has kept perennial trade disadvantage for a long period of time. In order to change the current trade situation, we must make in-depth analysis on the two countries' agricultural products trade status and their characteristics, thus target to development of trade strategy. This paper first introduces the current imbalance situation of the agricultural trade between China and the United States, then analyzes the causes of trade imbalance and its impact. Finally, some relevant countermeasures are putting forward, such as expanding the scale of the economy and agriculture; narrowing the gap between international and domestic regions and improving the quality and safety of agricultural products.
\end{abstract}

\section{Keywords}

Sino-US, Agricultural Products Trade, Present Situation, Countermeasures

\section{Introduction}

In recent years, the imbalance of agricultural products trade between Sino-US has become a major and sensitive issue in international trade. With the increasing scale of agricultural products trade, trade imbalance between Sino-US is getting worse. The trade deficit between Sino-US expanded from $\$ 2.2$ billion in 2007 to $\$ 18.4$ billion in 2014. The average annual growth rate is $42 \%$ [1] [2]. Continued expansion of the trade deficit will lead to Chinese excessive dependence on US agricultural products and had bad effect on the relationship be${ }^{\star}$ Corresponding author. 
tween the two countries. Therefore, the Sino-US agricultural trade imbalance has aroused great concern. The main performances of trade imbalance between the two countries are as follows: Chinese exports of agricultural products to the United States are lower than imports, and the export of agricultural products has been restrained [3]. The factors that affect the export of agricultural products in China include economic level, resource endowment difference and exchange rate volatility and so on. Another more important factor is the United States implementation on technical barriers to Chinese agricultural products, so that China has a resource endowment advantage of agricultural products which cannot give full play to its comparative advantage [4]. So we need to take targeted measures to solve these problems, to reverse the disadvantaged position of China in Sino-US agricultural trade.

\section{The Present Situation of Sino-US Trade in Agricultural Products}

In 2015, Chinese imports and exports of agricultural products both fell, and imports fell faster than the export volume. Annual agricultural trade volume of 18.756 billion US dollars (decreased 3.6\%). Among them, the export volume is 70.68 billion US dollars (decreased 1.8\%), the imports volume is 16.88 billion US dollars (decreased 4.6\%), and the trade deficit is 462.0 billion US dollars (decreased $8.7 \%$ ). Sino-US agricultural trade in 2015 totaled $\$ 30.04$ billion (decreased $11.3 \%$ year-on-year) US agricultural exports to China is 24.65 billion US dollars (decreased 14\%), and Chinese agricultural exports to the United States is 7.35 billion US dollars (decreased 1\%). [5] [6] Sino-US agricultural trade deficit is 17.3 billion US dollars which reached a new lower point in recent years. The trade of Sino-US agricultural products between 2006 and 2015 is shown in Table 1.

Table 1. Sino-US imports and exports of agricultural products. Unit: hundred million US dollars.

\begin{tabular}{ccccc}
\hline Yeas & Total trade volume & Total amount of exports & Total amount of imports & Trade balance \\
\hline 2006 & 92 & 40 & 52 & 12 \\
2007 & 110 & 44 & 66 & 22 \\
2008 & 168 & 51 & 117 & 66 \\
2009 & 171 & 47 & 124 & 77 \\
2010 & 214 & 57 & 157 & 99 \\
2011 & 256 & 67 & 190 & 123 \\
2012 & 307 & 71 & 236 & 165 \\
2013 & 338 & 72 & 265 & 192 \\
2014 & 360 & 74 & 286 & 212 \\
2015 & 320 & 73 & 246 & 173 \\
2016 & 375 & 75 & 256 & 181 \\
\hline
\end{tabular}

Data source: China Statistic Yearbook 2016. 
According to the statistics from US Department of Agriculture, in 2015, the Sino-US agricultural (livestock) products trade (the definition of US agricultural products does not contain aquatic products and forest products) general totaled to 24.57 billion US dollars, reaching the lowest point in the recent five-years (Table 2). In this case, the amount of agricultural products that the US exports to China was 20.25 billion US dollars, which is the third consecutive year of decline China has become the second largest agricultural export market of the US (while Canada has become the largest US agricultural export market of the US) China's agricultural exports to the United States amounted to 4.36 billion US dollars, unchanged from previous years, China is still the fourth largest US agricultural origin. [7] In 2015, the total trade in aquatic products between China and the United States was $\$ 3.661$ billion, reduced by $10.1 \%$, reaching the

Table 2. The Situation of Sino-US agricultural products in general trade (2011-2015). Unit: hundred million US dollars. A = Agricultural (livestock) products; $\mathrm{B}=$ Aquatic products.

\begin{tabular}{|c|c|c|c|c|c|c|}
\hline Years & Items & $\begin{array}{l}\text { Total amount } \\
\text { of imports }\end{array}$ & $\begin{array}{l}\text { Total amount } \\
\text { of exports }\end{array}$ & $\begin{array}{l}\text { Total trade } \\
\text { volume }\end{array}$ & $\begin{array}{l}\text { Trade } \\
\text { Deficit }\end{array}$ & $\begin{array}{l}\text { Trade } \\
\text { Surplus }\end{array}$ \\
\hline \multirow{2}{*}{2006} & A & 150.91 & 37.54 & 188.45 & 113.37 & - \\
\hline & B & 8.06 & 23.18 & 31.24 & - & 15.12 \\
\hline \multirow{2}{*}{2007} & A & 160.68 & 40.36 & 201.04 & 120.32 & - \\
\hline & B & 8.69 & 24.66 & 33.35 & - & 15.97 \\
\hline \multirow{2}{*}{2008} & A & 157.39 & 40.79 & 198.18 & 116.6 & - \\
\hline & B & 9.15 & 25.04 & 34.19 & - & 15.89 \\
\hline \multirow{2}{*}{2009} & A & 163.45 & 43.87 & 207.32 & 119.58 & - \\
\hline & B & 9.51 & 25.57 & 35.08 & - & 16.06 \\
\hline \multirow[b]{2}{*}{2010} & A & 179.72 & 44.33 & 224.05 & 135.39 & - \\
\hline & B & 9.47 & 26.06 & 35.53 & - & 16.59 \\
\hline \multirow{2}{*}{2011} & A & 188.98 & 39.92 & 228.9 & 149.06 & - \\
\hline & B & 11.44 & 26.55 & 37.99 & - & 15.11 \\
\hline \multirow{2}{*}{2012} & A & 258.59 & 45.32 & 303.91 & 213.27 & - \\
\hline & B & 11.29 & 26.70 & 37.99 & - & 15.41 \\
\hline \multirow{2}{*}{2013} & A & 254.99 & 44.20 & 299.19 & 210.79 & - \\
\hline & B & 11.20 & 27.05 & 38.25 & - & 15.58 \\
\hline \multirow{2}{*}{2014} & A & 242.19 & 42.77 & 284.96 & 199.42 & - \\
\hline & B & 11.85 & 28.88 & 40.73 & - & 17.03 \\
\hline \multirow[b]{2}{*}{2015} & A & 202.05 & 43.65 & 245.7 & 158.4 & - \\
\hline & B & 10.41 & 26.20 & 36.61 & - & 15.79 \\
\hline \multirow{2}{*}{2016} & A & 232 & 49.25 & 281.25 & 182.7 & - \\
\hline & B & 12.23 & 26.80 & 39.13 & - & 16.90 \\
\hline
\end{tabular}

Data source: China Statistic Yearbook 2015. 
lowest point of 5 years. [8] Among them, Chinese exports to the United States amounted 2.62 billion US dollars, decreased 9.3\%; US exports to China amounted 1.041 billion US dollars, reduced by $12.2 \%$. A $7.9 \%$ reduction in trade surplus, which was $\$ 1779$ million, and this data is flat with the average of previous years.

\subsection{Chinese Agricultural Products Exports to the United States}

Although the growth of China's agricultural exports to the United States is also very fast, from 60.61 billion US dollars in 2006 to 7.35 billion US dollars in 2015, but the total export gap with the United States disparity, and because the export momentum is not as good as the US exports to China, the trade deficit widened from $\$ 1.86$ billion in 2006 to $\$ 17.3$ billion in 2015 .

In 2015, Chinese agricultural products exports to the United States amounted to $\$ 4.365$ billion, a slight increase of $2 \%$ from 2014 ( $\$ 4.28$ billion). Among them, the horticultural agricultural exports amounted to 2.448 billion US dollars, sugar and tropical agricultural products for 622 million US dollars, cereals and feed for 462 million, livestock and meat for 330 million US dollars, oilseeds and products for the 2.43 million, poultry and its products for 1.46 million, seeds for $\$ 122$ million, dairy products for $\$ 482,000$, and $\$ 375,000$ for tobacco and its products.

\subsection{United States Agricultural Products Exports to China}

China is the largest export market for agricultural products in the United States. By examining the changes in agricultural products trade between China and the United States, it suggests that US exports of agricultural products to China have grown rapidly between 2006 and 2013, and the exports have increased from US $\$ 7.921$ billion to US $\$ 28.832$ billion, with a net increase of 2.65 times. But the average annual exports are about 8 billion US dollars in 2008 reached 14.787 billion US dollars in 2014 reached 28.6 billion US dollars, 2015 downturn trend, down to 24.6 billion US dollars.

In 2015, US exports to Chinese agricultural products reached to $\$ 20.25$ billion, down nearly $20 \%$ from 2014 . Among them, soybean and other edible oilseeds for 10.66 billion US dollars, cereals and feed 4.890 billion US dollars, livestock and meat 1.872 billion US dollars, $\$ 1.031$ billion in horticultural products, cotton and cotton 870 million, $\$ 450$ million for dairy and its products, $\$ 197$ million for tobacco and its products, $\$ 121$ million for sugar and tropical crops, \$119 million for plant seeds and $\$ 29$ million for poultry and its products.

\section{Analysis of the Causes of Sino-US Agricultural Trade}

The trade imbalance between Sino-US in agricultural products is becoming increasingly serious. The first reason lies in the different conditions of the two countries at the macro level, so the resource endowment has significant difference, US agricultural products perennial oversupply while China is shown in short supply which resulting in a huge trade deficit. Besides, followed by Chinese 
rising exchange rate, the United States decide to raise technical barriers to trade. Chinese agricultural trade exports have been constrained. Therefore, this section will be analyzed from two aspects, namely, macro factors and micro factors, to analyze the causes of Sino-US agricultural trade.

\subsection{Macro Factors}

\subsubsection{Chinese Agricultural Products in Short Supply}

Although China is a major producer of agricultural products, but per capita agricultural production resources are very limited, in which the most prominent is cultivated land resources. As China is in the process of urbanization, urban land and industrial land continue to erode arable land resources, the annual net reduction of arable land hundreds of thousands of hectares, At present, Chinese arable land is only about one-tenth of the land, Chinese per capita arable land is far below the world average. In addition to the scarcity of natural resources in China, the slow development of agricultural mechanization is another major factor leading to low agricultural production. Chinese agricultural production is in the form of family contracted land the production scale is too small to achieve economies of scale, resulting in farmers unable to purchase large-scale agricultural machinery for mechanized production; and most of them can only be cultivated on plains and cannot be applied to Chinese complex and varied terrain. The combination of natural resources and agricultural science and technology levels has inhibited the growth of Chinese agricultural net output.

At the same time, Chinese agricultural demand has remained strong trend. The population of China continues to grow is the direct cause of the growing demand for agricultural products in China. In recent years, the Chinese population has continued to grow at a natural rate of 5 percentage points, and the ever-expanding population base has led to the ever-increasing demand for agricultural products. In addition, Chinese economy to maintain high-speed growth in the process of urbanization continue to advance the rapid growth of urban and rural incomes, urban residents to improve food consumption structure, rural food consumption levels increased rapidly, food consumption of non-direct consumption (feed Food and processing, etc.) and animal protein consumption increased rapidly. Supply and demand both sides lead to the current situation of Chinese agricultural products in short supply.

\subsubsection{US Agricultural Products Oversupply.}

The United States is a "country of agriculture", agriculture has been an important economic pillar of the country. US arable land is large, the population is relatively scarce, per capita cultivated land is about 7 times that of China, is the world 3 times. At the same time, the United States is rich in natural resources, the climate is very suitable for crop growth, therefore, agriculture is an important economic pillar of the country. The technology of the United States is very developed, attaches great importance to the application of science and technology in the field of agriculture, coupled with the government's strong support for 
agriculture, making the US agriculture has a strong competitive edge. The high quality of labor and the spread of agricultural mechanization make US agricultural productivity the world's forefront. The United States has entered the stage of modern agricultural production, using its unique natural conditions, modern science and technology and strong industrial base, to help she develop the world's largest, with the latest science and technology equipment and efficient agriculture. As the government's long-term implementation of agricultural protection measures, the US agricultural production is often surplus. The export of agricultural products has increased the number of jobs in the country and has drawn the domestic economy very well. Therefore, the United States has made agricultural exports as an important strategic policy for a long time. The total agricultural output of the United States is less than 3\% of its GDP. Its agricultural exports accounted for $9 \%$ of total exports, showing that its agricultural products in the domestic market oversupply situation.

\subsection{Micro Factors}

\subsubsection{Chinese Exchange Rate Kept Rising, Inhibiting the Export of Agricultural Products}

The exchange rate is the rate at which the currencies of the two countries are exchanged, which establishes the domestic price and the foreign price to establish the relative price of the goods participating in the trade and play the role of price conversion in the foreign trade activities. The exchange rate has a significant impact on the sale of goods between countries, is an important economic leverage, exchange rate fluctuations will be a country's trade balance and domestic economic activities have a strong impact.

The United States is an important source of imports of agricultural products in China, and is also an important country for exporting agricultural products. RMB exchange rate against the US dollar will inevitably reduce Chinese exports of agricultural products, increase Chinese imports of agricultural products from the United States.

After the appreciation of the RMB, Chinese foreign exchange settlement of agricultural products increased prices, then the US demand for Chinese agricultural products decreased, so the export scale to narrow. On the other hand, Chinese imports of agricultural products prices fell, because China only need to pay less $\mathrm{RMB}$ to exchange a certain unit of foreign exchange imports of certain units of US agricultural products, so Chinese demand for imported agricultural products, the scale of imports will be expanded. Even if the foreign currency prices of Chinese exports of agricultural products have not risen after the appreciation of the RMB, the same amount of foreign exchange earnings obtained by exports can only be exchanged for a smaller amount of RMB, which will also reduce the profits of agricultural exporters and thus inhibit exports. Therefore, in general, the appreciation of the RMB will inhibit the export of Chinese agricultural products, expand imports, thus forming a trade deficit. 


\subsubsection{US Technical Trade Barriers Limit the Export of Chinese Agricultural Products}

In 2008, after the US subprime mortgage crisis caused by the financial crisis, the overall weakness of the world economy. US domestic economic recovery is weak, the US-China trade deficit is very high. In this case, the United States set up barriers to China, leading to frequent trade frictions, the United States with a complete technical barriers to trade system, and on this basis to maintain human and animal and plant health and environmental protection in the name of the introduction of a series of new regulations And the new standards, to set obstacles for the Chinese agricultural products. The United States has nominated trade liberalization nominally, but as a world agricultural power and a strong agricultural country, the problem of overproduction of domestic agricultural products has long existed for a long time. In order to bring these surplus agricultural products into the international market to digest and prevent foreign low prices of agricultural products filled the domestic market and further increase market saturation, the United States to build a sound technical barriers to agricultural trade system for the domestic agricultural production and agriculture-related enterprises to create a good development space and relaxed living environment. As a developing country, Chinese technological development level is far behind the United States, which led to the weak nature of Chinese agricultural exports, mainly for the low technological content of agricultural products and quality is not up to standard. According to the relevant experts predict that the current level of Chinese agricultural quality behind the United States 10 years or 20 years, Chinese exports to the United States mainly to low value-added products, labor-intensive products and capital-intensive products as the leading high value Of the export of resource-intensive agricultural products still occupy a secondary position. Chinese agricultural production technology and the way behind the United States, leading to quality monitoring is difficult to achieve. At present, on the one hand, Chinese agricultural production is in the transition period from the emphasis on the quantity of agricultural products to the quality and safety of agricultural products. The quality and safety system of agricultural production has not yet been established, and the international agricultural product safety and safety standards have not been met. On the other hand, On the overall situation of Chinese agriculture, there are still a low degree of organization, the information is not sensitive enough and not the size of the characteristics of the scale. So China is difficult to achieve the uniform scale of production standards, which is difficult to achieve product quality and safety control monitoring purposes. While The United States in the 19th century on the implementation of standardized monitoring of agricultural production, the focus of agricultural products has been the implementation of hazard analysis and key control point management policy. And China has not yet fully implemented, which resulted in Chinese exports of agricultural products not passing the US inspection and quarantine, and reduces exports. 


\subsection{Comprehensive Analysis}

The main reason for the agricultural trade imbalance between China and the United States comes from the advantages of different resources in the two countries. The per capita arable land in the United States is much higher than that of China, and the economies of scale brought by agricultural mechanized production have led to the annual begging; while Chinese large population, not only led to a small per capita arable land, but also brought a huge demand for agricultural products, so that Chinese agricultural products need to import a large number from abroad.. This is in the Sino-US agricultural trade has been fully reflected: Chinese imports from the United States each year, soybean, soybean oil and other bulk agricultural products accounted for more than $90 \%$ of total imports. Due to the resource endowments in China and the United States, the trade deficit between China and the United States will not be eliminated for a long period of time, but the ever-expanding scale of agricultural trade will lead to Chinese over-reliance on US agricultural products and threaten Chinese food security. Therefore, China must actively respond to the imbalance between the two countries agricultural trade situation, reduce the trade deficit between the two countries agricultural trade.

The main way to alleviate the trade deficit between the two countries is to expand Chinese comparative share of agricultural products, Chinese aquatic products, tea and other agricultural products on the international trade market showed a strong comparative advantage, but these agricultural products in the United States when the export trade scale And the gap between other agricultural products is very small, trade advantage has been a serious suppression. This is because the United States using the exchange rate means and technical barriers to trade restrictions on Chinese exports to the existence of comparative advantages of agricultural products How to deal with the imbalance between China and the United States agricultural trade situation, and expand the advantages of Chinese agricultural trade exports, is the problem that we urgently need to solve.

\section{Impact of Sino-US Agricultural Trade Deficit on Chinese Economy}

What impact will the over-deficit of agricultural trade bring about? This section attempts to explore the impact of excessive trade deficit of agricultural products from three aspects: national food security, agricultural economic development and farmers' income.

\subsection{The Impact on Food Security}

As the development of Chinese agricultural market is lagging behind, the degree of organization of agricultural products into the market is low, the contradiction between production and sales is prominent, the balance between supply and demand is very fragile.

Therefore, with the rapid growth of trade deficit of agricultural products, and 
due to the lack of effective import protection, the international market for domestic agricultural products supply and demand balance significantly increased, exacerbated by Chinese various agricultural products market, especially the emerging agricultural market supply and demand and price fluctuations, the formation of a huge market risk. The end result is that low-cost imports of agricultural products, the domestic market was squeezed; and then high-priced imports of agricultural products, the loss of domestic wealth, and then lead to food security crisis.

\subsection{The Impact on the Growth of Agricultural Economic}

The trade deficit of agricultural products means that imports are larger than exports, and sales of domestic agricultural products will be affected. The prices of agricultural products will be reduced, the income of farmers will be reduced, the enthusiasm of The enthusiasm for planting food will be frustrated, and the normal production of agriculture will be affected, which will affect the development of agriculture. The annual growth rate of agricultural output is lower than the annual growth rate of gross domestic product. At this point, the development of agriculture is relatively lagging behind the development of the national economy, which will bring instability, is not conducive to the healthy development of the economy as a whole, the greater the scale of the deficit, the greater the risk will become. So we must take proper control of the matter.

\subsection{The Impact on the Income of Farmers}

To a certain extent, although the import of agricultural products can enrich the lives of farmers, but Chinese agricultural exports lacks of pricing power, often have thin profits, it is difficult to earn benefits through agricultural transactions. The reason is that the international agricultural market demand reduction, affecting the export of agricultural products in China, coupled with a substantial increase in imports of agricultural products, imports greater than exports, further impact on the domestic agricultural production market, affecting the enthusiasm of farmers production, and ultimately hinder the growth of farmers' income The we can see that the trade deficit of agricultural products is very unfavorable to the income generation of our peasants, so we must take measures to curb.

\section{Conclusion and Suggestions}

\subsection{Expand the Scale of the Economy and Agriculture}

\subsubsection{Speed up the Development of Rural Economy and Overall Economic Level}

First of all, we have to play the advantages of regional resources, reasonable and rational optimization of agricultural production layout; we also need to continuously improve the level of agricultural safety, and vigorously produce high-quality pollution-free agricultural products, so that we can speed up the 
realization of the quality of agricultural products in China, we can optimize the pattern of rural industry, vigorously develop the township agriculture and the second tertiary industry in rural area, promote the development of agricultural products processing industry, and vigorously produce high value-added agricultural products. Second, we should strengthen the level of agricultural industrialization. It is committed to support and improve the leading enterprises, strengthen and deepen the leading enterprises and farmers between the interests of the link mechanism. What's more, it can actively participate in the cooperation of agricultural organizations, broaden the marketing channels of agricultural products, build green channels for agricultural products, vigorously carry out the development strategy to go out, so as to improve the level of opening up; thirdly, it is necessary to vigorously support the construction of rural infrastructure. The support system and guarantee system for agricultural development should focus on optimizing, speed up the scientific and technological innovation and application of economic and agricultural construction, actively create a new agricultural security system, and lay a solid foundation for improving the comprehensive agricultural capacity.

\subsubsection{Develop and Improve the Industrialization of Agriculture}

We need to vigorously develop the "leading enterprises + cooperatives + farmers" agricultural industrialization management model. Compared with the United States, the current level of agricultural industrialization in China is relatively low. The scale of agriculture is small. The production, processing, storage, transportation and sales and other links are independent separation, which has not yet formed an integrated scale. Compared with the market trading model, "leading enterprises + farmers" industrial management model obtains an objective profit. There is no enthusiasm for agricultural industrialization. The business model of "leading enterprises + cooperatives + farmers" is a more efficient mode of agricultural industrialization, leading enterprises, agricultural cooperatives and farmers that are interdependent: Leading enterprises to cooperatives and farmers as the basis, to solve the production of raw materials of the problem; farmers to cooperatives and enterprises to rely on to solve the problem of agricultural sales. While increasing the income of farmers, expanding the scale of agriculture and economic scale can also be realised.

\subsection{Narrow the Gap between International and Domestic Regions}

\subsubsection{Narrow the Gap between China and the United States}

First of all, we should vigorously develop scientific and technological innovation: speed up the progress of agricultural science and technology, the introduction of leading agricultural products, enhance the role of agricultural science and technology market, pay attention to personnel training, increase agricultural science and technology research. We will implement the spirit of the documents put forward by the Central Committee, accelerate the implementation of the reform of the grassroots agricultural extension system and the construction of demon- 
stration counties, enhance the promotion of agricultural technology, improve the transformation of agricultural science and technology, make use of the advanced nature of science and technology and enhance the level of scientific farming. At the same time, actively organize the promotion of science and technology. And around the endowment of the advantages of agricultural products and technology to promote and training

Second, we should improve the overall quality of the population: At present, due to the backwardness of rural education in China, the agricultural labor force in China is generally low in cultural level and the overall quality has a certain gap with the United States, which is bound to have an impact on Chinese agricultural production technology, thus affecting the export of Chinese agricultural products. In the United States, most farmers have undergraduate and above qualifications, some of the agricultural institutions have been trained, can be a good use of modern science and technology, the books on the use of things to the actual agricultural production, per capita agricultural products Production far more than China. Therefore, to improve the overall quality of agricultural labor force, so that farmers will become more professional, and adapt to the current technological development requirements, narrowing the gap with the United States. This is a long process, in which the important means is to develop with the rural labor force to adapt to the vocational skills education and training. First of all, we should implement nine-year compulsory education in rural areas, actively promote vocational and technical education, expand technical education in agriculture, delay the employment of rural students and extend students' reading time. Second, vigorously promote rural vocational and technical education, focusing on the promotion of the application of agricultural technology, thereby enhancing the agricultural labor force of agricultural skills and comprehensive knowledge, so as to better use in agricultural production, improve agricultural production efficiency, narrowing the gap with the US agricultural technology. Third, pay attention to rural adult education, government departments should establish a learning place in rural areas or educational institutions, education for farmers, cultivate with cultural quality, skilled agricultural labor force. Finally, we should increase learning and exchange opportunities, contact with the latest agricultural development technology at home and abroad, narrow the gap between international and domestic regions, and increase the export of Chinese agricultural products

\subsubsection{Narrow the Gap in Economic Development between Chinese Regions}

The opening and development of a country's internal specific region of the economy is facing two levels of choice: one is inter-regional opening, the opening of the domestic region, and the other is the international opening, that is, the specific region of the country is open to foreign countries. In accordance with the development experience of developed countries such as the United States, economic development and opening up at the international and regional levels 
will be synchronized to promote the development. The following three factors play a significant role in promoting Chinese interregional opening and interregional economic development:

First, the adjustment of Chinese opening policy. The state should adjust the policy of opening up nationwide. The policy adjustment can not only stimulate the investment of foreign capital, but also realize the simultaneous development of trade in inland and coastal areas. Second, China needs to transform the stage of economic transformation and development. With the rapid development of Chinese economy in recent years, the competitiveness of non-state enterprises has been improved, and the problems of state-owned enterprises have been gradually revealed. At the grassroots level, the way in which problems are solved has revealed the trend of transforming state-owned enterprises with non-state enterprises. With the deepening of the trend, the transformation and development of Chinese economy will increase the speed of cross-regional investment, to promote regional economic restructuring and development and inter-regional opening is very favorable. The third is to improve and optimize interregional transport facilities and communication facilities. At present, the main factor restricting Chinese regional economic development is the problem of transportation and communication systems. Increased efforts to improve interregional transport facilities and communications equipment will lead to a significant increase in operational efficiency among regions, thus accelerating the development of economies across China.

\subsection{Improve the Quality and Safety of Agricultural Products}

\subsubsection{Constantly Optimize the External Environment of Agricultural Production}

First of all, China should learn from the experience of the United States and other developed countries, improve the existing agricultural protection laws and regulations, set up pollution prevention and control laws and regulations, increase the emphasis on agricultural environmental protection law.

Secondly, the government departments should actively cooperate with each other to create the corresponding conditions to integrate the agricultural production environment, establish agricultural production and external environmental protection and governance institutions, from the government departments at all levels to protect the laws and regulations to implement; Finally, the Chinese government should vigorously support green agriculture, encourage green production, increase agricultural subsidies and the benefits of green production costs, vigorously support green agriculture and green production, and the corresponding farmers to provide economic and technical Of the support, so that the external environment of agricultural production has been greatly improved.

\subsubsection{Improve the Quality Supervision System of Agricultural Products}

The government has assumed greater responsibility and risk in the supervision 
of quality and safety of agricultural products. Its supervision is gradually expanding and expanding with the chain of agricultural production, circulation and consumption. During this process, the government departments involved are also increasing. The United States and other developed countries, the advantages of agricultural product quality supervision system is that the functional departments not only clear division of labor, cooperation is also very harmonious, while the information can be shared between departments, regulatory action in an orderly manner. Therefore, China should learn from each other, learn from the developed countries, construct of a reasonable quality of the organization, the coordination of operational departments, the same pace of action, the system stability and continuity of the quality supervision system.

\section{Acknowledgements}

This paper is supported by Social Science Project of Shandong Agricultural University (No. 23899), Humanities and social science research project in Shandong province (No. J16WC49); Teaching and Reform Project of Shandong Agricultural University (X2017093).

This paper is one of the author's research outcomes as academic visitor in Lancaster University in UK from 1 Sep. 2018 to 1 March in 2019.

\section{Conflicts of Interest}

The authors declare no conflicts of interest regarding the publication of this paper.

\section{References}

[1] Goonatilake, Lalith (2010) Challenges in Agro-Food Exports: Building the Quality Infrastructure. International Trade Forum, 88-92.

[2] Grigsby (1986) The Effect of Exchange Rate Distortions on the Case of Argentina. American Journal of Agricultural Economics, 68.

[3] Jaffee, S. (2004) Standards and Agro-Food Exports from Developing Countries: Rebalancing the Debate. World Bank, 33-48.

[4] Schlueter (2009) Regulatory SPS Instruments in Meat Trade, Agricultural and Resource Economics. Discussion Paper, 123-136.

[5] Caniato, M. and Vaccari, M. (2014) Usingsocial Network and Stakeholder Analysis to Help Evaluate Infectious Waste Management: A Step towards a Holistic Assessment. Waste Management, 34, 938-951.

https://doi.org/10.1016/j.wasman.2014.02.011

[6] Copeland, B.R. and Taylor, M.S. (1994) North-South Trade and the Environment. The Quarterly Journal of Economics, 109, 755-787. https://doi.org/10.2307/2118421

[7] De Stefano, L. (2016) Facing the Water Framework Directive Challenges: A Baseline of Stakeholder Participation in the European Union. Journal of Environmental Management, 91, 1332-1340.

[8] Jia, L. (2016) Opportunities and Challenges Faced by Xinjiang Enterprises in the Marketing under the Strategy Background of One Belt One Road. Essaeme, 41-45. 